\title{
Intracranial post-clipping residual or recurrent aneurysms: Current status and treatment options (Review)
}

\author{
JIANMIN PIAO ${ }^{1}$, TENGFEI LUAN ${ }^{1}$, LAI QU ${ }^{2}$ and JINLU YU ${ }^{1}$ \\ Departments of ${ }^{1}$ Neurosurgery and ${ }^{2}$ Intensive Care, The First Hospital of Jilin University, Changchun, Jilin 130021, P.R. China
}

Received February 14, 2021; Accepted April 8, 2021

DOI: $10.3892 / \mathrm{mi} .2021 .1$

\begin{abstract}
Following the clipping of intracranial aneurysms, post-clipping residual or recurrent aneurysms (PCRRAs) can occur. In recent years, the incidence of PCRRAs has increased due to a prolonged follow-up period and advanced imaging techniques. However, several aspects of intracranial PCRRAs remain unclear. Therefore, the present study performed an in-depth review of the literature on PCRRAs. Herein, a summary of PCRRAs that can be divided into the following two categories is presented: i) Those occurring after the incomplete clipping of an aneurysm, where the residual aneurysm regrows into a PCRRA; and ii) those occurring after the complete clipping of an aneurysm, in which a de novo aneurysm occurs at the original aneurysm site. Currently, digital subtracted angiography remains the gold standard for the imaging diagnosis of PCRRAs as it can eliminate metallic clip artifacts. Intracranial symptomatic PCRRAs should be actively treated, particularly those that have ruptured. A number of methods are currently available for the treatment of intracranial PCRRAs; these mainly include re-clipping, endovascular treatment (EVT) and bypass surgery. Currently, re-clipping remains the most effective method used to treat PCRRAs; however, it is a very difficult procedure to perform. EVT can also be used to treat intracranial PCRRAs. EVT methods include coiling (stent- or balloon-assisted) and flow-diverting stents (or coiling-assisted). Bypass surgery can be selected for difficult-to-treat, complex PCRRAs. On the whole, following appropriate treatment, the majority of intracranial PCRRAs achieve a high occlusion rate and a good prognosis.
\end{abstract}

Correspondence to: Dr Jinlu Yu, Department of Neurosurgery, The First Hospital of Jilin University, 1 Xinmin Avenue, Changchun, Jilin 130021, P.R. China

E-mail: jlyu@jlu.edu.cn

Abbreviations: CTA, computed tomography angiography; DSA, digital subtraction angiography; PCRRA, post-clipping residual or recurrent aneurysm; EVT, endovascular treatment; ICG-VA, indocyanine green video angiography; FDSs, flow-diverting stents; STA, superficial temporal artery

Key words: post-clipping residual or recurrent aneurysms, surgical treatment, endovascular treatment

\section{Contents}
1. Introduction
2. Incidence
3. Pathogenesis and classification
4. Bleeding risk
5. Clinical presentation
6. Imaging examination
7. Indications for treatment
8. Treatment options
9. Treatment outcomes
10. Conclusions

\section{Introduction}

Currently, treatments for intracranial aneurysms include clipping and coiling (1). Compared to coiling, the clipping of an intracranial aneurysm is associated with relatively low residual and recurrence rates (2-4). However, following the clipping of intracranial aneurysms, post-clipping residual or recurrent aneurysms (PCRRAs) can occur $(5,6)$.

Previously, intracranial PCRRAs were considered rare; however, their incidence has increased due to prolonged follow-up periods and advanced imaging techniques $(7,8)$. The clinical characteristics of PCRRAs are complex. For some PCRRAs, particularly for those that rupture, prompt treatment may be required, including re-clipping, endovascular treatment (EVT) and even bypass surgery $(5,6,9)$.

Currently, little is known about PCRRAs; to date, at least to the best of our knowledge, no in-depth review has previously been published to explore intracranial PCRRAs. Therefore, in the present study, 'intracranial aneurysm', 'clipping', 'residual', 'recurrent', 'remnant', and 'recanalized' were used as search terms to retrieve related literature from the PubMed database. Subsequently, the current status and treatment options for PCRRAs were reviewed in an aim to improve the current understanding of intracranial PCRRAs.

\section{Incidence}

The incidence of intracranial PCRRAs varies substantially, and cases are mainly divided into recurrent cases, following complete clipping, and residual cases, following incomplete clipping (10). The incidence of PCRRAs after complete clipping 
is $1.8-8.0 \%$, and the annual incidence is $0.14-0.52 \%(11-14)$. However, not all aneurysms undergo complete clipping, even when surgeons consider that complete clipping has been achieved (Fig. 1). Of these cases, 5.2-5.9\% will have residual aneurysms; the incidence of regrowth is $1.83-2.1 \%$ per year, and the total regrowth rate is $12.5-27 \%$ (14-19).

The difference in the incidence of PCRRAs is mainly related to factors, such as the length of follow-up (20). A PCRRA can occur at any point in time, and the specific timing is not clear (21). The time to occurrence may be lengthy; for instance, the average time to occurrence was 10.6 years in the study published by Kivelev et al (20), which is much longer than the average time to occurrence after coiling (3.3 years). Compared with intracranial post-embolization residual or recurrent aneurysms, the incidence of PCRRAs is significantly lower (22-25).

\section{Pathogenesis and classification}

Intracranial PCRRAs can be classified as recurrent and residual post-clipping aneurysms. The mechanisms of occurrence of these two types of intracranial PCRRAs are illustrated in Fig. 2.

Recurrent post-clipping aneurysms. There are two possible reasons that recurrent post-clipping aneurysms may occur. First, clipping may not completely correct a pre-existing weakness in the parent artery and aneurysm neck, and the aneurysm may therefore continue to grow. Second, clipping may weaken the vascular wall of the aneurysm neck and parent artery and thereby induce de novo aneurysms in these weaker regions $(7,26)$.

Residual post-clipping aneurysms. These cases have been attributed to incomplete initial clipping or slipping of a clip after complete clipping has been achieved (20). Slipping occurs when an aneurysm neck is wide and calcified; therefore, the clip moves to the distal end of the aneurysm during clipping, causing the residual aneurysm to gradually grow under the impact of blood flow $(6,27)$.

In addition, the risk factors for intracranial aneurysm include smoking, hypertension, dyslipidemia, diabetes, a family history of the condition, multiple aneurysms and sex (a higher incidence is observed in females), all of which are also factors that contribute to PCRRAs $(21,28,29)$.

\section{Bleeding risk}

Intracranial PCRRAs are associated with a high risk of rupture of. Previous studies have reported that the incidence of bleeding is approximately $1.4-2.2 \%$ within the first decade of a PCRRA, and the incidence increases to $9-12.4 \%$ in the 20th year $(5,9,30)$. This is far higher than the incidence of subarachnoid hemorrhage in the normal population (0.072\%) (31). However, the bleeding rate of PCRRAs is lower than that in incidentally discovered unruptured aneurysms (32).

Several factors can influence whether intracranial bleeding occurs in PCRRAs, among which, the PCRRA size is the greatest risk factor. Drake and Vanderlinden (33) found that the incidence of re-bleeding was $17 \%$ in small PCRRAs, whereas it was $23 \%$ in large PCRRAs.

\section{Clinical presentation}

The clinical presentation of intracranial PCRRAs can be classified as ruptured or unruptured as described below:

Ruptured aneurysms. Ruptured intracranial PCRRAs are mainly characterized by headaches, nausea, vomiting, stiffness, possible limb paralysis, coma and, in severe cases, death (4). These are similar to the symptoms of the initial intracranial aneurysm rupture (34).

Unruptured aneurysms. Unruptured intracranial PCRRAs are characterized by headaches, progressive vision loss, ocular nerve paralysis, hemiplegia, dysphonia and trigeminal neuralgia (35). These symptoms are related to a variety of factors, including the size, shape and location of the PCRRA (36). However, a number of intracranial PCRRAs exhibit no symptoms or signs $(37,38)$.

\section{Imaging examination}

Currently, the diagnosis of an intracranial PCRRA includes digital subtraction angiography (DSA), computed tomography angiography (CTA) and other examinations $(39,40)$.

$D S A$. At present, DSA is the gold standard for the diagnosis and follow-up of PCRRAs as it can effectively exclude the influence of metallic clip artifacts (41). The diagnosis rate of three-dimensional DSA is much higher than that of two-dimensional DSA (42). Performing intraoperative DSA after aneurysm clipping, particularly in a hybrid operating room, can reduce the incidence of a PCRRA $(43,44)$.

CTA. CTA is a novel investigation method that can be used to accurately detect intracranial aneurysms (45). Sun et al (46) found that CTA had a sensitivity of $71 \%$ and a specificity of 94\% when detecting intracranial PCRRAs. New technology associated with CTA includes image processing with metal artifact reduction software. This process significantly reduces the metal artifacts caused by clipping in PCRRA imaging, which can improve its diagnostic rate of PCRRAs (47). In addition, detection using dual-energy CTA is less affected by clip artifacts and may thus be more effective for the diagnosis of PCRRAs with $\leq 2$ clips $(48,49)$.

Other inspection methods. Other than intraoperative DSA, practical indocyanine green video angiography (ICG-VA) has become one of the most widely used examination methods. ICG-VA can be used to assess blood flow through the parent artery and to determine whether residual aneurysm remains (50). Özgiray et al (51) treated 109 cases of intracranial aneurysms with clipping and found that ICG-VA could effectively assess the patency of the circulation. However, aneurysm remnants can occur in $6.5 \%$ cases after successful clipping (51).

\section{Indications for treatment}

Whether intracranial PCRRAs are treated depends mainly on certain factors, such as whether the PCRRAs are ruptured, 

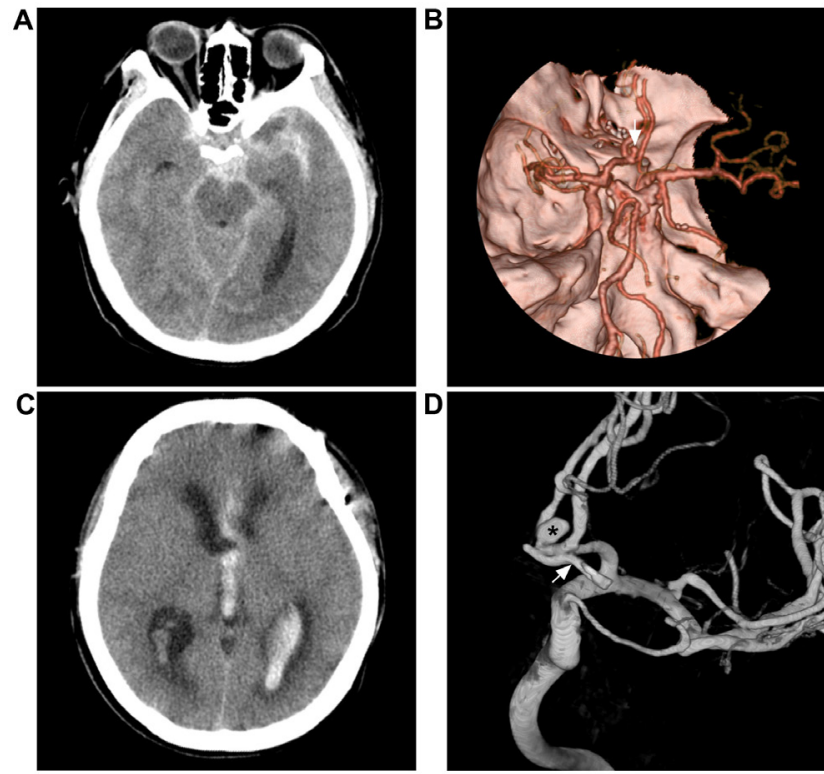

Figure 1. Repeated subarachnoid hemorrhage following incomplete clipping. (A) Head CT scan illustrating subarachnoid hemorrhage at the suprasellar cistern. (B) CTA reveals an anterior communicating aneurysm (white arrow). (C) CT scan illustrating intraventricular hemorrhage from re-rupture of the anterior communicating aneurysm recurrent two months after microsurgical clipping. (D) Angiogram illustrating the aneurysm clip (white arrow) under the remnant aneurysm (black asterisk). For the case presented, the surgeon considered that complete clipping had been achieved. CT, computed tomography; CTA, computed tomography angiography.

their necks (e.g., the width of the neck), the size and sites of the PCRRAs and the willingness of the patients and their families for treatment (35).

Bleeding. When PCRRA rupture results in bleeding, the PCRRA requires treatment (34).

Size. The size is of particular importance when selecting PCRRA treatment options. Kivelev et al suggested that when a PCRRA aneurysm is $\geq 3 \mathrm{~mm}$, surgical treatment should be considered. When a PCRRA is $1-2 \mathrm{~mm}$ in size, it should be closely monitored (20).

Site. The treatment selected for a PCRRA is associated with its location. Jabbarli et al (52) examined 112 PCRRA cases and noted that the location (e.g., anterior cerebral artery $>$ internal carotid artery $>$ posterior circulation $>$ middle cerebral artery) was an important risk factor for PCRRAs. Therefore, treatment should be selected when an aneurysm is in the anterior communicating artery (52).

Other factors. When PCRRAs become giant aneurysms due to thrombosis or when the rupture of the PCRRA produces an intracranial hematoma resulting in space occupying effect, craniotomy should be seriously considered (53).

\section{Treatment options}

A number of treatment options are available for PCRRAs, mainly including re-clipping of the aneurysm, EVT and bypass surgery (53).
Clipping. Re-clipping remains the main method used for the treatment of PCRRAs. This procedure is much more difficult to perform than the initial clipping, mainly as the scarred and adhered brain tissue renders the exposure of the operative field and the parent artery difficult, and the previously placed clip interferes with the ability to expose the aneurysm neck. Additionally, intraoperative rebleeding can occur while the existing clip is being moved $(7,20,54)$. The re-clipping of an intracranial PCRRA should proceed according to the following sequence: Dissection toward the aneurysm, bypass assistance if necessary, mobilization of the existing clip and placement of the new clip(s) $(7,20)$.

Among the events mentioned above, whether to move the existing clip during re-clipping is a key decision that must be made; in addition, previous studies have proposed that it is beneficial to move an existing aneurysm clip in order to allow sufficient space in which to operate $(55,56)$. However, another study did not suggest the intraoperative removal of an existing aneurysm clip as this may cause a tear in the aneurysm (57). Therefore, whether an existing clip is moved should be determined based on the needs of the procedure.

In addition, if the PCRRA is large in size or contains a thrombosis, it can be cut after the PCRRA is trapped. The presence of a thick and atherosclerotic aneurysm wall may necessitate the suturing of the edges of the incised sac to facilitate clip placement at the neck (20).

EVT. Currently, EVT is the main effective treatment method for PCRRAs (58). It also has a higher success rate for blocking PCRRAs. Gross et al (59) described 43 cases of intracranial PCRRAs in which EVT was used, and they found that $79 \%$ of the PCRRAs were completely occluded, $14 \%$ had residual neck tissue and $7 \%$ had stable small dome residues. A number of EVT methods are available for the treatment of intracranial PCRRAs, including coiling (or stent- or balloon-assisted methods) and flow-diverting stents (FDSs) (or coil embolism-assisted) (60-63).

Single coiling is the most practical method to treat an intracranial PCRRA, particularly for PCRRAs with a narrow neck (Fig. 3). Gross et al (59) used single coiling in 18 cases of narrow-neck PCRRAs and observed no recurrence during an average follow-up period of 3.9 years. However, in wide-necked, large, complex PCRRAs, stent- or balloon-assisted EVT is required $(61,64,65)$. The recanalization rate is high in complex PCRRAs (66).

FDSs are a new type of stent that has emerged in recent years that can effectively treat intracranial PCRRAs. An FDS is a flexible, low-porosity, endoluminal stent that is capable of altering the hemodynamics of the parent artery and aneurysm, resulting in the formation of a thrombosis in the aneurysm. FDSs can also guarantee blood flow through the normal para-aneurysm branch and are therefore especially suitable for large, wide-neck PCRRAs $(67,68)$. For instance, in a previous study, seven cases of PCRRA were treated by Adeeb et al (8), and all were completely embolized without sequelae following the implantation of FDSs.

However, the treatment of a PCRRA using FDSs often requires a longer time to achieve complete occlusion. For example, Dornbos et al (69) performed FDS implantation in 


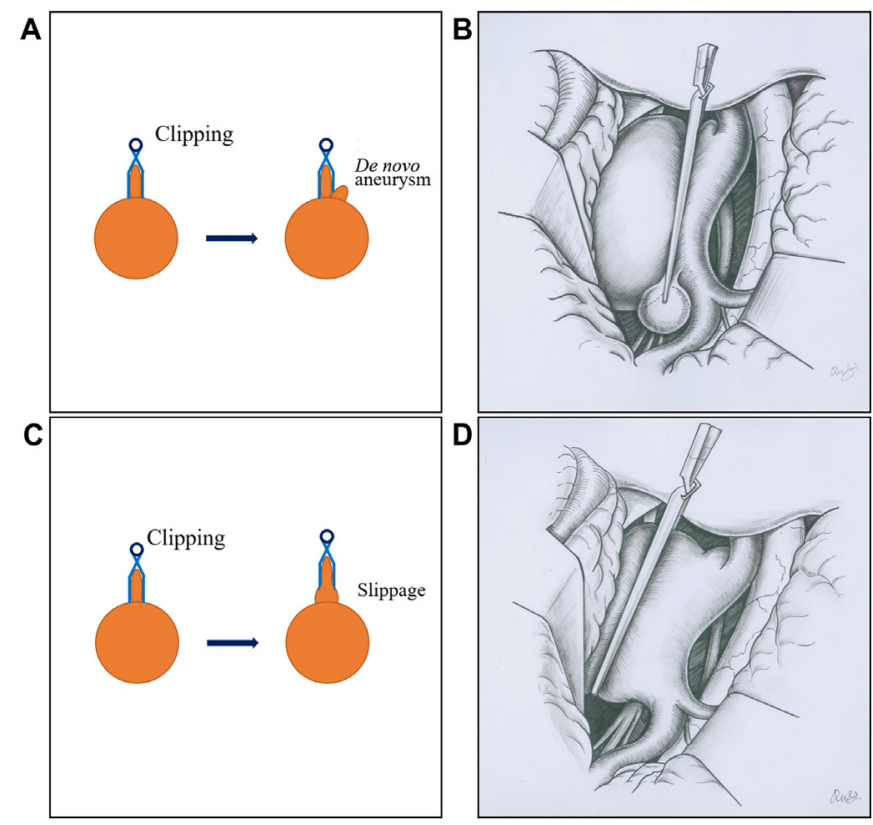

Figure 2. Classification of intracranial PCRRAs. (A and B) Images show the development of a de novo aneurysm after clipping. (C and D) Images show a post-clipping residual aneurysm due to clip slippage. PCRRAs, post-clipping residual or recurrent aneurysms.

four cases of intracranial PCRRAs, and post-operative DSA revealed that $80 \%$ of the PCRRAs had embolized at six months post-operatively, while $100 \%$ had embolized at 12 months post-operatively.

Bypass surgery. Bypass surgery is considered as a 'last resort' for the treatment of complex PCRRAs that are difficult to treat (20). Bypass surgery can be divided into three categories according to its purpose, as follows: i) To provide permanent and adequate blood flow for the distal parent artery of the PCRRA; ii) to prevent cerebral ischemia caused by the temporary occlusion of the parent artery; and iii) to isolate the PCRRA and reconstruct the parent artery (53).

The selection of bypass surgery that is most appropriate depends on the individual case. Kivelev et al (20) described 25 cases of intracranial PCRRA in which bypass treatment was applied, including clipping of PCRRAs with bypass treatment, PCRRA trapping with bypass treatment and proximal occlusion of PCRRAs with bypass treatment. Over an average post-operative follow-up period of 3.5 years, 23 patients exhibited a good prognosis, and their modified Rankin scale score was $<2$ points (20).

During bypass surgery for intracranial PCRRAs, the most commonly used supply arteries include the following: i) The superficial temporal artery (STA) and the occipital artery, both of which are suitable for middle- and low-flow bypass surgery; and ii) the radial artery and the great saphenous vein (required to connect the external carotid system), which are ideal interposition grafts for high-flow bypass surgery (20,70-72).

\section{Treatment outcomes}

The treatment of PCRRAs can achieve satisfactory outcomes $(55,73,74)$. As regards the occlusion rate in the

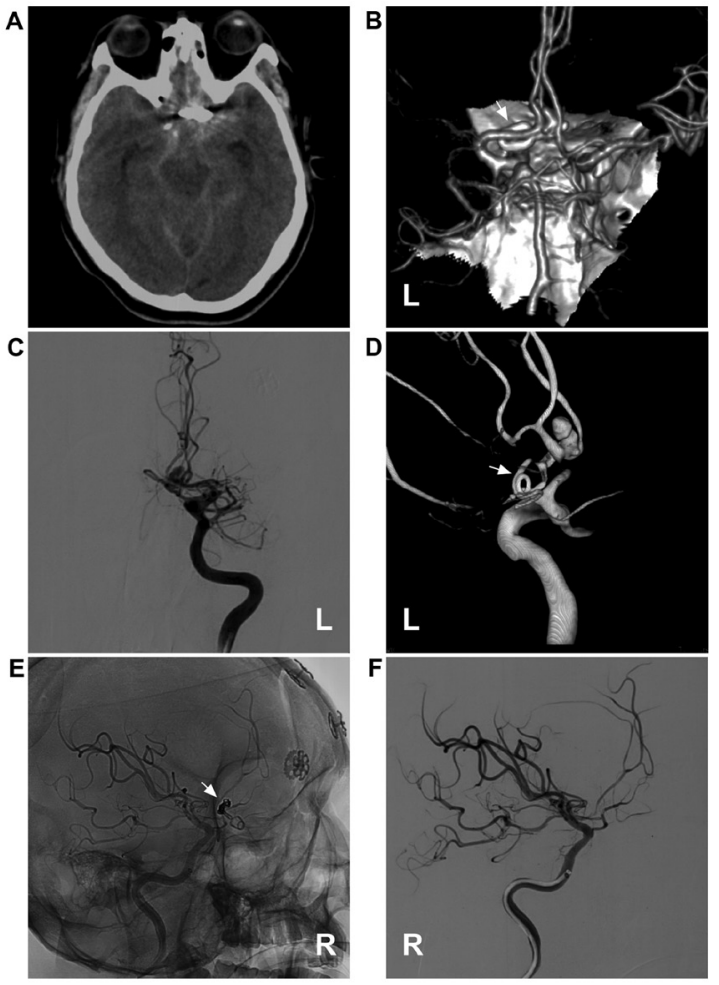

Figure 3. Coiling of the post-clipping recurrent aneurysm. (A) Brain CT scan illustrating subarachnoid hemorrhage at the suprasellar cistern; a metallic artefact can be seen. (B) Brain CTA illustrating the recurrent anterior communicating aneurysm; the clip can be seen (white arrow). (C) DSA of the left internal carotid artery illustrating the moyamoya-like vessels in the region of middle cerebral artery. (D) Three-dimensional DSA illustrating the recurrent anterior communicating aneurysm and the clip (white arrow). (E) Unsubtracted and (F) subtracted angiogram illustrating that the aneurysm is coiled completely. For the case presented in the image, the first clipping was performed five years ago. CT, computed tomography; CTA, computed tomography angiography; DSA, digital subtraction angiography; L, left; R, right.

treatment of PCRRAs, the rate of complete obliteration has been shown to be $72-89$, and $84 \%$ of the patients have been shown to have a good functional outcome $(55,61,73,74)$. Moreover, no evidence is currently available to confirm that treatment results are related to the size and sites of PCRRAs or to whether surgical clipping and EVT are used (61).

The surgical clipping of PCRRAs requires the adhered tissues to be stripped, resulting in repeated brain injury. Therefore, these procedures are much more difficult to perform and involve several complications, including cerebral infarction, meningitis and epilepsy (53). Drake et al (74) reported that the disability rate was $7 \%$ and the mortality rate was $5.2 \%$. Giannotta and Litofsky (55) reported a mortality rate of $15.8 \%$, which was higher than that reported in the study by Drake et al (74).

EVT produces less damage to the brain and has a significantly lower risk of post-operative complications than clipping (20,21). Gross et al (59) described 60 PCRRA patients who were treated with EVT, and the post-operative procedural permanent morbidity and mortality rates were only 3 and $2 \%$, respectively. Li et al (75) performed EVT in 43 cases of intracranial PCRRA, 36 (84\%) of which had complete occlusion, and no re-bleeding occurred during the follow-up period (average, 34.5 months). 
In conclusion, in the majority of intracranial PCRRAs, active treatment results in a high occlusion rate and an improved clinical prognosis.

\section{Conclusions}

After an intracranial aneurysm is clipped, in some cases, PCRRAs can occur. Symptomatic PCRRAs require prompt treatment, particularly those that have ruptured. A number of treatment methods are available for intracranial PCRRAs, mainly including re-clipping and EVT. Bypass surgery can be selected for difficult-to-treat, complex PCRRAs. Following appropriate treatment, the majority of intracranial PCRRAs can achieve a high occlusion rate and an improved prognosis.

\section{Acknowledgements}

Not applicable.

\section{Funding}

No funding was received.

\section{Availability of data and materials}

The datasets used and/or analyzed during the current study are available from the corresponding author on reasonable request.

\section{Authors' contributions}

JY and JP designed the study and drafted the manuscript. TL and LQ collected and analyzed the clinical data. JY and JP confirm the authenticity of all the raw data. JY critically revised the manuscript. LQ constructed and prepared the figures. All authors read and approved the final manuscript.

\section{Ethics approval and consent to participate}

Ethics approval was not required for the present review article from our institution. Written informed consent was obtained from the patients whose data are depicted in the figures.

\section{Patient consent for publication}

Written informed consent was obtained from the patients for publication of the relevant information.

\section{Competing interests}

The authors declare that they have no competing interests.

\section{References}

1. Bender MT, Wendt H, Monarch T, Lin LM, Jiang B, Huang J, Coon AL, Tamargo RJ and Colby GP: Shifting treatment paradigms for ruptured aneurysms from open surgery to endovascular therapy over 25 years. World Neurosurg 106: 919-924, 2017.

2. Spetzler RF, Zabramski JM, McDougall CG, Albuquerque FC, Hills NK, Wallace RC and Nakaji P: Analysis of saccular aneurysms in the barrow ruptured aneurysm trial. J Neurosurg 124: $120-125,2018$
3. Fotakopoulos G, Tsianaka E, Fountas K, Makris D, Spyrou M and Hernesniemi J: Clipping versus coiling in anterior circulation ruptured intracranial aneurysms: A meta-analysis. World Neurosurg 104: 482-488, 2017.

4. Lawton MT and Vates GE: Subarachnoid hemorrhage. N Engl J Med 377: 257-266, 2017.

5. Yamakawa H, Sakai N, Takenaka K, Yoshimura S, Andoh T, Yamada H, Ohkuma A, Takada M and Funakoshi T: Clinical analysis of recurrent subarachnoid hemorrhage after neck clipping surgery. Neurol Med Chir (Tokyo) 37: 380-386, 1997.

6. Asgari S, Wanke I, Schoch B and Stolke D: Recurrent hemorrhage after initially complete occlusion of intracranial aneurysms. Neurosurg Rev 26: 269-274, 2003.

7. Spiotta AM, Hui F, Schuette A and Moskowitz SI: Patterns of aneurysm recurrence after microsurgical clip obliteration. Neurosurgery 72: 65-69, 2013.

8. Adeeb N, Griessenauer CJ, Moore J, Stapleton CJ, Patel AB Gupta R, Patel AS, Thomas AJ and Ogilvy CS: Pipeline embolization device for recurrent cerebral aneurysms after microsurgical clipping. World Neurosurg 93: 341-345, 2016.

9. Tsutsumi K, Ueki K, Usui M, Kwak S and Kirino T: Risk of recurrent subarachnoid hemorrhage after complete obliteration of cerebral aneurysms. Stroke 29: 2511-2513, 1998.

10. Owen CM, Montemurro N and Lawton MT: Microsurgical management of residual and recurrent aneurysms after coiling and clipping: An experience with 97 patients. Neurosurgery 62 (Suppl 1): S92-S102, 2015.

11. Byrne JV, Sohn MJ, Molyneux AJ and Chir B: Five-year experience in using coil embolization for ruptured intracranial aneurysms: Outcomes and incidence of late rebleeding. J Neurosurg 90: 656-663, 1999.

12. David CA, Vishteh AG, Spetzler RF, Lemole M, Lawton MT and Partovi S: Late angiographic follow-up review of surgically treated aneurysms. J Neurosurg 91: 396-401, 1999.

13. Tsutsumi K, Ueki K, Morita A, Usui M and Kirino T: Risk of aneurysm recurrence in patients with clipped cerebral aneurysms: Results of long-term follow-up angiography. Stroke 32: 1191-1194, 2001.

14. Brown MA, Parish J, Guandique CF, Payner TD, Horner T, Leipzig T, Rupani KV, Kim R, Bohnstedt BN and Cohen-Gadol AA: A long-term study of durability and risk factors for aneurysm recurrence after microsurgical clip ligation. J Neurosurg 126: 819-824, 2017.

15. Sindou M, Acevedo JC and Turjman F: Aneurysmal remnants after microsurgical clipping: Classification and results from a prospective angiographic study (in a consecutive series of 305 operated intracranial aneurysms). Acta Neurochir (Wien) 140: 1153-1159, 1998.

16. Thornton J, Bashir Q, Aletich VA, Debrun GM, Ausman JI and Charbel FT: What Percentage of surgically clipped intracranial aneurysms Have residual necks? Neurosurgery 46: 1294-1300, 2000.

17. Thines L, Dehdashti AR, Howard P, Da Costa L, Wallace MC, Willinsky RA, Tymianski M, Lejeune JP and Agid R: Postoperative assessment of clipped aneurysms with 64-slice computerized tomography angiography. Neurosurgery 67: 844-854, 2010.

18. Goksu E, Korkmaz E, Akyuz M, Ozgur O, Sindel T and Tuncer R: The analysis of long-term follow-up screening in patients with surgically treated intracranial aneurysms. Turk Neurosurg 25: 404-409, 2015

19. Burkhardt JK, Chua MHJ, Weiss M, Do ASS, Winkler EA and Lawton MT: Risk of aneurysm residual regrowth, recurrence, and de novo aneurysm formation after microsurgical clip occlusion based on Follow-up with catheter angiography. World Neurosurg 106: 74-84, 2017.

20. Kivelev J, Tanikawa R, Noda K, Hernesniemi J, Niemelä M, Takizawa K, Tsuboi T, Ohta N, Miyata S, Oda J, et al: Open surgery for recurrent intracranial aneurysms: Techniques and long-term outcomes. World Neurosurg 96: 1-9, 2016.

21. Wermer MJ, Rinkel GJ, Greebe P, Albrecht KW, Dirven CM and Tulleken CA: Late recurrence of subarachnoid hemorrhage after treatment for ruptured aneurysms: Patient characteristics and outcomes. Neurosurgery 56: 197-204, 2005.

22. Shi L, Yuan Y, Guo Y and Yu J: Intracranial post-embolization residual or recurrent aneurysms: Current management using surgical clipping. Interv Neuroradiol 22: 413-419, 2016.

23. Spetzler RF, McDougall CG, Albuquerque FC, Zabramski JM, Hills NK, Partovi S, Nakaji P and Wallace RC: The barrow ruptured aneurysm trial: 3-year results. J Neurosurg 119: 146-157, 2013. 
24. Bernat AL, Clarencon F, André A, Nouet A, Clémenceau S, Sourour NA, Di Maria F, Degos V, Golmard JL, Cornu P and Boch AL: Risk factors for angiographic recurrence after treatment of unruptured intracranial aneurysms: Outcomes from a series of 178 unruptured aneurysms treated by regular coiling or surgery. J Neuroradiol 44: 298-307, 2017.

25. Ferns SP, Sprengers ME, van Rooij WJ, Rinkel GJ, van Rijn JC, Bipat S, Sluzewski M and Majoie CB: Coiling of intracranial aneurysms: A systematic review on initial occlusion and reopening and retreatment rates. Stroke 40 e523-e529, 2009

26. Ebina K, Suzuki M, Andoh A, Saitoh K and Iwabuchi T: Recurrence of cerebral aneurysm after initial neck clipping. Neurosurgery 11: 764-768, 1982.

27. Yang TK and Kim CJ: Recurrent subarachnoid hemorrhage after complete obliteration of intracranial aneurysm. J Korean Neurosurg Soc 46: 492-494, 2009.

28. Kuhn AL, de Macedo Rodrigues K, Lozano JD, Rex DE, Massari F, Tamura T, Howk M, Brooks C, L'Heureux J, Gounis MJ, et al: Use of the Pipeline embolization device for recurrent and residual cerebral aneurysms: A safety and efficacy analysis with short-term follow-up. J Neurointerv Surg 9: 1208-1213, 2017

29. Sakaki T, Tominaga M, Miyamoto K, Tsunoda S and Hiasa Y: Clinical studies of de novo aneurysms. Neurosurgery 32: 512-517, 1993.

30. Tsutsumi K, Ueki K, Usui M, Kwak S and Kirino T: Risk of subarachnoid hemorrhage after surgical treatment of unruptured cerebral aneurysms. Stroke 30: 1181-1184, 1999.

31. Linn FH, Rinkel GJ, Algra A and van Gijn J: Incidence of subarachnoid hemorrhage: Role of region, year, and rate of computed tomography: A meta-analysis. Stroke 27: 625-629, 1996.

32. Juvela S, Poussa K, Lehto H and Porras M: Natural history of unruptured intracranial aneurysms: A long-term follow-up study. Stroke 44: 2414-2421, 2013

33. Drake CG and Vanderlinden RG: The late consequences of incomplete surgical treatment of cerebral aneurysms. J Neurosurg 27: 226-238, 1967.

34. Zhao J, Lin H, Summers R, Yang M, Cousins BG and Tsui J: Current treatment strategies for intracranial aneurysms: An overview. Angiology 69: 17-30, 2018.

35. Boulouis G, Rodriguez-Regent C, Rasolonjatovo EC, Ben Hassen W, Trystram D, Edjlali-Goujon M, Meder JF, Oppenheim C and Naggara O: Unruptured intracranial aneurysms: An updated review of current concepts for risk factors, detection and management. Rev Neurol (Paris) 173: 542-551, 2017.

36. Kobayashi S, Moroi J, Hikichi K, Yoshioka S, Saito H, Tanabe J and Ishikawa T: Treatment of recurrent intracranial aneurysms after neck clipping: Novel classification scheme and management strategies. Oper Neurosurg (Hagerstown) 13: 670-678, 2017.

37. Bruneau M, Rynkowski M, Smida-Rynkowska K, Brotchi J, De Witte $\mathrm{O}$ and Lubicz B: Long-term follow-up survey reveals a high yield, up to $30 \%$ of patients presenting newly detected aneurysms more than 10 years after ruptured intracranial aneurysms clipping. Neurosurg Rev 34: 485-496, 2011.

38. Hoh BL, Carter BS, Putman CM and Ogilvy CS: Important factors for a combined neurovascular team to consider in selecting a treatment modality for patients with previously clipped residual and recurrent intracranial aneurysms. Neurosurgery 52: 732-739, 2003

39. Uysal E, Ozel A, Erturk SM, Kirdar O and Basak M: Comparison of multislice computed tomography angiography and digital subtraction angiography in the detection of residual or recurrent aneurysm after surgical clipping with titanium clips. Acta Neurochir (Wien) 151: 131-135, 2009.

40. Wachter D, Psychogios M, Knauth M and Rohde V: IvACT after aneurysm clipping as an alternative to digital subtraction angiography-first experiences. Cent Eur Neurosurg 71: 121-125, 2010.

41. Roessler K, Krawagna M, Dorfler A, Buchfelder M and Ganslandt O: Essentials in intraoperative indocyanine green videoangiography assessment for intracranial aneurysm surgery: Conclusions from 295 consecutively clipped aneurysms and review of the literature. Neurosurg Focus 36: E7, 2014.

42. Kumar S, Gaikwad SB and Mishra NK: 3D Rotational angiography in Follow-up of clipped intracranial aneurysms. ISRN Radiol 2014: 935280, 2014
43. Dammann P, Jagersberg M, Kulcsar Z, Radovanovic I, Schaller K and Bijlenga P: Clipping of ruptured intracranial aneurysms in a hybrid room environment-a case-control study. Acta Neurochir (Wien) 159: 1291-1298, 2017.

44. Ares WJ, Kenmuir CL, Panczykowski DM, Weiner GM, Jadhav AP, Jovin TG, Gross BA and Jankowitz BT: A Critical analysis of the utility of intraoperative angiography. World Neurosurg 110: e84-e89, 2018.

45. Pjontek R, Onenkoprulu B, Scholz B, Kyriakou Y, Schubert GA, Nikoubashman O, Othman A, Wiesmann M and Brockmann MA: Metal artifact reduction for flat panel detector intravenous CT angiography in patients with intracranial metallic implants after endovascular and surgical treatment. J Neurointerv Surg 8: 824-829, 2016.

46. Sun H, Ma J, Liu Y, Lan Z and You C: Diagnosing residual or recurrent cerebral aneurysms after clipping by computed tomographic angiography: Meta-analysis. Neurol India 61: 51-55, 2013.

47. Dunet V, Bernasconi M, Hajdu SD, Meuli RA, Daniel RT and Zerlauth JB: Impact of metal artifact reduction software on image quality of gemstone spectral imaging dual-energy cerebral $\mathrm{CT}$ angiography after intracranial aneurysm clipping. Neuroradiology 59: 845-852, 2017.

48. Fahrendorf DM, Goericke SL, Oezkan N, Breyer T, Hussain S, Sandalcioglu EI, Sure U, Forsting M and Gizewski ER: The value of dual-energy CTA for control of surgically clipped aneurysms. Eur Radiol 21: 2193-2201, 2011.

49. Dolati P, Eichberg D, Wong JH and Goyal M: The utility of dual-energy computed tomographic angiography for the evaluation of brain aneurysms after surgical clipping: A prospective study. World Neurosurg 84: 1362-1371, 2015.

50. Kumar V, Jagetia A, Singh D, Srivastava AK and Tandon MS: Comparison of efficacy of intraoperative indocyanine green videoangiography in clipping of anterior circulation aneurysms with postoperative digital subtraction angiography. J Neurosci Rural Pract 8: 342-345, 2017.

51. Özgiray E, Akture E, Patel N, Baggott C, Bozkurt M, Niemann D and Başkaya MK: How reliable and accurate is indocyanine green video angiography in the evaluation of aneurysm obliteration? Clin Neurol Neurosurg 115: 870-878, 2013.

52. Jabbarli R, Pierscianek D, Wrede K, Dammann P, Schlamann M, Forsting M, Müller O and Sure U: Aneurysm remnant after clipping: The risks and consequences. J Neurosurg 125: 1249-1255, 2016.

53. Hokari M, Kazumara K, Nakayama N, Ushikoshi S, Sugiyama T, Asaoka K, Uchida K, Shimbo D, Itamoto K, Yokoyama Y, et al: Treatment of recurrent intracranial aneurysms after clipping: A report of 23 cases and a review of the literature. World Neurosurg 92: 434-444, 2016.

54. Benet A and Lawton MT: Clip reconstruction of a recurrent anterior communicating artery aneurysm after previous Clipping: 3-Dimensional operative video. Oper Neurosurg (Hagerstown) 13: 647, 2017.

55. Giannotta SL and Litofsky NS: Reoperative management of intracranial aneurysms. J Neurosurg 83: 387-393, 1995.

56. el-Beltagy M, Muroi C, Roth P, Fandino J, Imhof HG and Yonekawa Y: Recurrent intracranial aneurysms after successful neck clipping. World Neurosurg 74: 472-477, 2010.

57. Sakaki T, Takeshima T, Tominaga M, Hashimoto $H$ and Kawaguchi S: Recurrence of ICA-PCoA aneurysms after neck clipping. J Neurosurg 80: 58-63, 1994.

58. Cekirge HS, Islak C, Firat MM, Kocer N and Saatci I: Endovascular coil embolization of residual or recurrent aneurysms after surgical clipping. Acta Radiol 41: 111-115, 2000.

59. Gross BA, Albuquerque FC, Moon K, Ducruet AF and McDougall CG: Endovascular treatment of previously clipped aneurysms: Continued evolution of hybrid neurosurgery. J Neurointerv Surg 9: 169-172, 2017.

60. Mangiafico S, Cellerini M, Villa G, Ammannati F, Paoli L and Mennonna P: Endovascular coiling of aneurysm remnants after clipping in patients with Follow-up. A single center experience. Interv Neuroradiol 11: 41-48, 2005.

61. Rabinstein AA and Nichols DA: Endovascular coil embolization of cerebral aneurysm remnants after incomplete surgical obliteration. Stroke 33: 1809-1815, 2002.

62. Siddiqui AH, Kan P, Abla AA, Hopkins LN and Levy EI: Complications after treatment with pipeline embolization for giant distal intracranial aneurysms with or without coil embolization. Neurosurgery 71: E509-E513, 2012. 
63. Lin LM, Iyer RR, Bender MT, Monarch T, Colby GP, Huang J, Tamargo RJ and Coon AL: Rescue treatment with pipeline embolization for postsurgical clipping recurrences of anterior communicating artery region aneurysms. Interv Neurol 6: 135-146, 2017.

64. Chung J, Park IS, Park H, Hwang SH, Jung JM and Han JW: Endovascular coil embolization after clipping: Endovascular treatment of incompletely clipped or recurred cerebral aneurysms. J Cerebrovasc Endovasc Neurosurg 16: 262-267, 2014.

65. Takeshita T, Nagamine T, Ishihara K and Kaku Y: Stent-assisted coil embolization of a recurrent posterior cerebral artery aneurysm following surgical clipping. Neuroradiol J 30: 99-103, 2017.

66. Molyneux AJ, Birks J, Clarke A, Sneade M and Kerr RS: The durability of endovascular coiling versus neurosurgical clipping of ruptured cerebral aneurysms: 18 year follow-up of the UK cohort of the International Subarachnoid Aneurysm Trial (ISAT). Lancet 385: 691-697, 2015.

67. Ding D, Starke RM, Evans AJ, Jensen ME and Liu KC: Endovascular treatment of recurrent intracranial aneurysms following previous microsurgical clipping with the Pipeline Embolization Device. J Clin Neurosci 21: 1241-1244, 2014.

68. Romagna A, Ladisich B, Schwartz C, Winkler PA and Rahman AA: Flow-diverter stents in the endovascular treatment of remnants in previously clipped ruptured aneurysms: A feasibility study. Interv Neuroradiol 25: 144-149, 2019.

69. Dornbos D III, Karras CL, Wenger N, Priddy B, Youssef P, Nimjee SM and Powers CJ: Pipeline embolization device for recurrence of previously treated aneurysms. Neurosurg Focus 42: E8, 2017.
70. Pancucci G, Potts MB, Rodriguez-Hernandez A, Andrade H, Guo L and Lawton MT: Rescue bypass for revascularization after ischemic complications in the treatment of giant or complex intracranial aneurysms. World Neurosurg 83: 912-920, 2015.

71. Shi X, Qian H, Fang T, Zhang Y, Sun Y and Liu F: Management of complex intracranial aneurysms with bypass surgery: A technique application and experience in 93 patients. Neurosurg Rev 38: 109-120, 2015.

72. Strickland BA, Attenello F and Russin JJ: Extracranial to intracranial bypass for the treatment of cerebral aneurysms in the pediatric population. J Clin Neurosci 34: 6-10, 2016.

73. Boet R, Poon WS and Yu SC: The management of residual and recurrent intracranial aneurysms after previous endovascular or surgical treatment-a report of eighteen cases. Acta Neurochir (Wien) 143: 1093-1101, 2001.

74. Drake CG, Friedman AH and Peerless SJ: Failed aneurysm surgery. Reoperation in 115 cases. J Neurosurg 61: 848-856, 1984.

75. Li K, Cho YD, Kang HS, Kim JE, Han MH and Lee YM: Endovascular management for retreatment of postsurgical intracranial aneurysms. Neuroradiology 55: 1345-1353, 2013.

(7) $\Theta$ This work is licensed under a Creative Commons EY NG ND Attribution-NonCommercial-NoDerivatives 4.0 International (CC BY-NC-ND 4.0) License. 